\title{
Propriedades e Características da Quitosana Obtida a Partir do Exoesqueleto de Caranguejo-Uçá Utilizando Radiação de Microondas
}

\author{
Abreu, F. O. M. S., Cavalcante, L. G., Doudement, P. V., Castro, A. M., Nascimento A. P. \\ Laboratório de Materiais, Centro de Ciências Tecnológicas, Universidade de Fortaleza, UNIFOR
}

Matos, J. E. X

Núcleo de Pesquisas Tecnológicas, Centro de Ciências Tecnológicas, Universidade de Fortaleza, UNIFOR

\begin{abstract}
Resumo: Neste trabalho, obteve-se quitosana a partir do exoesqueleto de Ucides cordatus cordatus, comumente denominado caranguejo-uçá, em um processo no qual a conversão da quitina em quitosana foi feita via reação convencional $(\mathrm{QV})$ e também usando radiação de microondas $(\mathrm{QP})$. Caracterizaram-se as quitosanas produzidas em função do grau de desacetilação (GD), viscosidade intrínseca ( $\eta$ e massa molar viscosimétrica média (Mz), avaliando-se as propriedades em comparação com uma amostra de quitosana de caranguejo comercial (QC). A quitosana produzida por radiação de microondas apresentou grau de desacetilação maior do que a produzida via reação convencional e a quitosana comercial, com valores obtidos por titulação de 77\%, 65\% e 71\% para QP, QV e QC, respectivamente. No teste de solubilidade, a amostra QP dissolveu mais facilmente em solução de ácido acético diluído do que a QC, enquanto que a amostra QV não apresentou boa solubilidade em solução de ácido acético 2\%, devido ao seu baixo grau de desacetilação. A massa molar viscosimétrica das amostras QP e QC foi $412.600 \mathrm{~g} / \mathrm{mol} \mathrm{e} 336.100 \mathrm{~g} / \mathrm{mol}$, respectivamente, situando-se dentro dos padrões reportados na literatura. Em suma, pode-se afirmar que a conversão de quitina em quitosana por radiação com microondas é um método vantajoso, pois houve redução considerável de consumo de energia e de tempo em relação ao processo convencional, sendo que a amostra QP mostrou propriedades superiores à amostra QV, e propriedades equivalentes à amostra comercial QC. Além disso, o método empregado pode ser ajustado para produção de quitosana em escala industrial.
\end{abstract}

Palavras-chave: Quitosana, Ucides cordatus cordatus, caranguejo, radiação de micro-ondas, grau de desacetilação.

\section{Development of New Method to Obtain Chitosan from the Exoskeleton of Crabs Using Microwave Radiation}

\begin{abstract}
In this work, chitosan was obtained from crab-uçá exoskeleton (Ucides cordatus cordatus), where conversion into chitosan was made with two techniques, namely conventional heating and using microwave radiation. The product obtained by radiation $(\mathrm{QP})$ and conventional process $(\mathrm{QV})$ were characterized and compared to a chitosan commercial sample (QC) regarding to the deacetylation degree (GD), viscosity average molar mass (Mz) and related properties. QP presented higher GD than QV and QC samples, with values of 77\%, 65\% and 71\%, respectively. The solubility test showed that QP dissolved more easily in diluted acetic acid than QC, while QV did not dissolve in acid aqueous solution due to the low GD. QP also showed higher Mz than QC, with values of $412.600 \mathrm{~g} / \mathrm{mol}$ and $336.100 \mathrm{~g} / \mathrm{mol}$, respectively. These properties agree with those reported in the literature. Therefore, the synthesis of chitosan from chitin using microwave reaction proved to be successful, since it is easier, faster and less expensive due to the time and energy optimization in comparison to the conventional process. The chitosan sample obtained displayed even better properties than a commercial sample. In addition, this process can be adjusted for production in industrial scale.
\end{abstract}

Keywords: Chitosan, Ucides cordatus cordatus, crab, microwave radiation, deacetylation degree.

\section{Introdução}

Os polissacarídeos tem sido muito estudados nos últimos anos devido a suas características de biocompatibilidade, biodegradabilidade e atoxicidade ${ }^{[1]}$. A quitosana é um derivativo funcional obtido a partir da desacetilação da quitina, que se encontra presente abundantemente no exoesqueleto de crustáceos como o camarão e o caranguejo ${ }^{[2,3]}$. A quitosana é um polissacarídeo composto de unidades de 2-amino-
2-deoxi-D-glicopiranose e 2-acetamido-2-deoxi-Dglicopiranose, e apresenta composição variável em função do grau médio de acetilação e da massa molar aparente $^{[2]}$. A Figura 1 ilustra a estrutura química da quitosana e da quitina.

As propriedades da quitosana dependem principalmente de sua massa molar aparente e do grau de desacetilação ${ }^{[4]}$, pois ambos os parâmetros são 


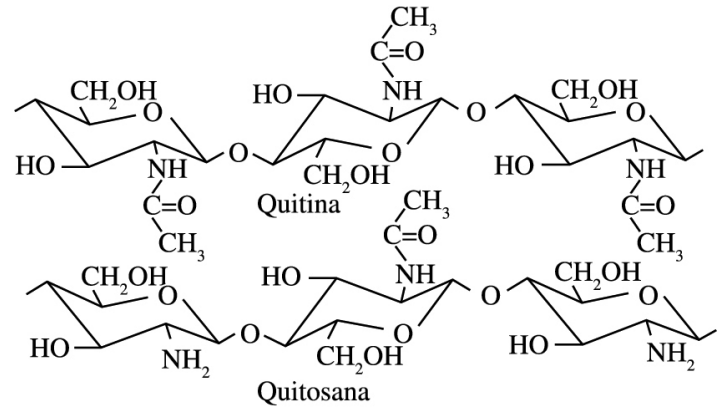

Figura 1. Estrutura química da quitina e da quitosana.

importantes para definir a solubilidade do polissacarídeo em meio aquoso. Enquanto a quitina é inerte e insolúvel, seu derivativo é reativo e solúvel em ácidos fracos, podendo ser caracterizado como um polieletrólito catiônico $^{[3]}$. Isto se deve ao fato da quitosana em meio ácido apresentar uma grande quantidade de grupos amino protonados $\left(-\mathrm{NH}_{3}^{+}\right)$na sua cadeia polimérica o que causa repulsão eletrostática entre as cadeias e maior solvatação em água, resultando em uma maior solubilidade ${ }^{[5]}$.

As carapaças de caranguejo são fontes ricas em quitina. No Brasil, as principais áreas de ocorrência e produção deste crustáceo estão concentradas nas regiões Norte e Nordeste, as quais contribuem com $70 \%$ da produção nacional. O caranguejo-uçá -Ucides cordatus cordatus- é o segundo maior crustáceo encontrado nos ecossistemas de mangue, sendo preferencialmente explorado para o consumo humano ${ }^{[6]}$. Muitos métodos tem sido desenvolvidos para recuperação dos componentes químicos, como proteínas, quitina e carotenóides entre outros, a partir de resíduos do processamento de crustáceos $^{[7]}$. Em Fortaleza - CE, centenas de quilos de carapaças de caranguejo são descartadas diariamente pelos restaurantes. Em função disso, tem-se estudado a utilização da carapaça de caranguejo visando sua aplicação em diversas áreas, dentre outras, na produção de biomassa para extração de quitina utilizada em produtos alimentícios e cosméticos ${ }^{[8]}$.

A viabilização de um processo simples e eficaz para a transformação da carapaça de caranguejo em quitosana visa beneficiar resíduos que não tem valor agregado para novas aplicações.

A reação de desacetilação da quitina para sua conversão em quitosana se dá comumente por digestão em solução de hidróxido de sódio (40-60\%), usando tempos que variam de 30 minutos a 24 horas, e temperatura relativamente elevada, de 50 a $130{ }^{\circ} \mathrm{C}^{[9]}$. O rendimento depende destas condições de reação, entre outras variáveis ${ }^{[10]}$. O estudo da influência dos parâmetros de reação no grau de desacetilação e na massa molar viscosimétrica da quitosana foi reportada recentemente por Moura et al. ${ }^{[9]}$. Estes mesmos fatores influenciam o grau de eficiência da desacetilação e as características da quitosana obtida ${ }^{[10]}$. Recentemente, foi proposta a reação de desacetilação da quitina oriunda de crustáceos do golfo arábico usando radiação por micro-ondas, obtendo-se quitosana com propriedades similares às obtidas pelos métodos convencionais ${ }^{[11]}$. Neste trabalho, foi desenvolvida uma metodologia para a obtenção da quitosana a partir de carapaças de caranguejo-uçá usando radiação de micro-ondas, buscando-se otimizar tempo e energia no processo em relação ao processo convencional. A quitosana obtida foi caracterizada em função das suas principais propriedades como o grau de desacetilação e massa molar viscosimétrica média e comparada com uma amostra de quitosana de caranguejo comercial para avaliação do método de síntese desenvolvido.

\section{Experimental}

O processo de obtenção da quitosana a partir da carapaça de caranguejo envolveu as etapas ilustradas na Figura 2. A quitosana produzida foi comparada com uma amostra de quitosana de caranguejo comercial (Polymar, CE) em relação a suas propriedades e características.

\section{Preparação das Carapaças de Caranguejo}

Foram coletados $10 \mathrm{~kg}$ da porção cefalotórax de caranguejo-uçá -Ucides cordatus cordatus- provenientes da primeira safra pós-defeso no Delta do Parnaíba, que se constituem um resíduo da culinária gastronômica local. As carapaças foram limpas por imersão em solução aquosa de $\mathrm{NaOH}$ a $4 \%$ por $6 \mathrm{~h}$ para dissolver resíduos de carne e gordura dos caranguejos seguido por imersão em solução de $\mathrm{NaClO} 2,5 \%$ por $6 \mathrm{~h}$. As carapaças foram secas a $40{ }^{\circ} \mathrm{C}$, moídas em liquidificador industrial Max Machine (LQ-15), e posteriormente peneiradas na granulometria média de $1 \mathrm{~mm}$, obtendo-se 4,5 $\mathrm{Kg}$ de pó de carapaça.

\section{Processo de obtenção da quitina}

A quitina foi obtida através de etapas de desmineralização, desproteinização e filtração. A desmineralização de $4 \mathrm{Kg}$ de pó de carapaças foi feita através da adição lenta de $40 \mathrm{~L}$ de $\mathrm{HCl}$ 1,5 M a temperatura ambiente, para controlar o volume de espuma proveniente da reação, por um período total de $48 \mathrm{~h}$. O material foi lavado com uma solução aquosa de $\mathrm{NaOH}$ a $10 \%$ repetidas vezes até atingir um $\mathrm{pH}$ igual a 5 , e foi seco na estufa a $60{ }^{\circ} \mathrm{C}$ durante 48 horas. Para a obtenção da quitina, adicionou-se solução de $\mathrm{NaOH}$ a $4 \%$ na temperatura de $80{ }^{\circ} \mathrm{C}$ para a desproteinização e a retirada de gordura. A adição foi realizada de forma controlada e posteriormente, a mistura foi mantida sob agitação lenta e constante durante 72 horas. A quitina obtida foi separada por decantação, lavada e seca em estufa por 48 horas.

\section{Processo de obtenção da quitosana}

A conversão da quitina em quitosana foi feita através de dois métodos distintos. Inicialmente, adicionou-se 40 gramas de quitina seca em uma solução de $\mathrm{NaOH}$ a $50 \%$ na proporção de $1: 5 \mathrm{~m} / \mathrm{v}$ (quitina:solução $\mathrm{NaOH}$ ) e deixou-se em repouso durante 24 horas. Posteriormente, procedeu-se a reação de desacetilação via radiação de micro-ondas usando um processo adaptado de $\mathrm{Al}$ Sagheer et al. ${ }^{[11]}$. Resumidamente, a solução foi colocada no forno de micro-ondas convencional por 15 minutos a uma potência de $270 \mathrm{~W}$, no qual agitou-se a mistura para homogeneização e repetiu-se a operação mais uma vez usando a mesma potência e o mesmo período de 
T. amb.

1. $\mathrm{NaOH}$ a $4 \%$

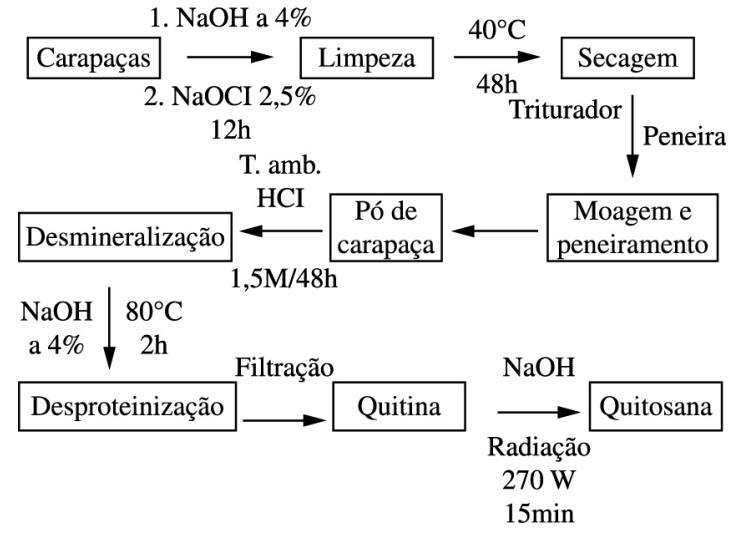

Figura 2. Etapas de obtenção da quitina e quitosana a partir do exoesqueleto do caranguejo.

tempo, totalizando $30 \mathrm{~min}$ de radiação. Pelo processo convencional, a quitina após o período de repouso por 24 h em solução de $\mathrm{NaOH}$ a $50 \%$, foi aquecida em manta elétrica (Quimis Modelo Q321A) na potência de 700W sob refluxo na temperatura de $120{ }^{\circ} \mathrm{C}$ por duas horas. Após a reação, foi realizada a lavagem com água corrente até a neutralização dos produtos obtidos, a amostra obtida por radiação de micro-ondas $\left(\mathrm{Q}_{\mathrm{P}}\right)$ e por aquecimento convencional $\left(\mathrm{Q}_{\mathrm{V}}\right)$.

\section{Caracterização da quitosana}

O grau de desacetilação da quitosana produzida pelos diferentes métodos $\left(\mathrm{Q}_{\mathrm{P}} \mathrm{e} \mathrm{Q}_{\mathrm{V}}\right)$ foi determinado pelos métodos de titulação potenciométrica e espectroscopia no infravermelho. Para fins de comparação, caracterizou-se também uma amostra comercial de quitosana $\left(\mathrm{Q}_{\mathrm{C}}\right)$. A titulação potenciométrica foi adaptada da descrita por De Oliveira e Nunes ${ }^{[12]}$ em um pHmetro HANNA Instruments (HI 253). Dissolveu-se 0,5g de quitosana em solução padronizada de $\mathrm{HCl}$ 0,1M e titulou-se, em duplicata, com solução padrão de $\mathrm{NaOH} 0,05 \mathrm{M}$ sob agitação contínua. O grau de desacetilação (GD) da quitosana foi calculado usando a Equação 1:

$$
G D \%=\frac{161 \times[\mathrm{NaOH}] \times\left(V_{2}-V_{1}\right)}{m} \times 100
$$

Onde: 161 (g/mol) é massa molar da unidade glicosídica, $[\mathrm{NaOH}]$ é a concentração molar utilizada na titulação, $\left(\mathrm{V}_{2}-\mathrm{V}_{1}\right)$ é o volume da solução de $\mathrm{NaOH}$ entre os dois pontos de inflexão, m é massa (g) da quitosana utilizada no experimento.

A viscosidade e a massa molar do polissacarídeo foram determinadas medindo-se o tempo de escoamento, em quintuplicata, de soluções poliméricas de várias concentrações em ácido acético $2 \%$ v/v em um viscosímetro de Otswald em banho termostático a $25^{\circ} \mathrm{C}$, conforme metodologia descrita em trabalho anterior ${ }^{[13]}$. A viscosidade específica e a viscosidade específica reduzida dos polímeros foram determinadas segundo as Equações 2 e 3:

$$
\eta_{\text {esp }}=\left(\mathrm{t}-\mathrm{t}_{0} / \mathrm{t}_{0}\right)
$$

$$
\eta_{\text {esp red }}=\left(\eta_{\text {esp }} / \mathrm{c}\right)
$$

Onde: $\eta_{\text {esp }}=$ viscosidade específica, $\mathrm{t}=$ tempo de escoamento da solução no viscosímetro; $\mathrm{t}_{0}=$ tempo de escoamento do solvente puro no viscosímetro, $\mathrm{c}=$ concentração em gramas de polímero em $100 \mathrm{~mL}$ de solução e $\eta_{\text {esp red }}=$ viscosidade específica reduzida.

A viscosidade intrínseca é definida através da Equação 4 e a determinação da massa molar viscosimétrica dos polímeros $\left(\mathrm{M}_{\mathrm{z}}\right)$ foi estimada através da equação de Mark-Kuhn-Houwink-Sakurada, indicada na Equação 5:

$$
\begin{aligned}
& \eta_{\text {intrinseca }}=[\eta]=\lim \left(\eta_{\text {esp red }}\right) \\
& \mathrm{c} \rightarrow 0
\end{aligned}
$$

$$
[\eta]=\kappa\left(M_{z}\right)^{\alpha}
$$

Onde: [ $\rceil$ ] é a viscosidade intrínseca do polímero $[\mathrm{mL} / \mathrm{g}], \mathrm{M}_{\mathrm{Z}}$ é a massa molar viscosimétrica $\alpha$ e $\kappa$ são constantes que são dependentes das interações entre o polímero e solvente. Para quitosana na forma neutra, $\alpha=0,76$ e $\kappa=0,074^{[14]}$.

A solubilidade da quitosana foi estimada dissolvendo a frio $0,5 \mathrm{~g}$ de material em solução $2 \%$ de ácido acético. Após decorrido $30 \mathrm{~min}$, avaliou-se a solubilidade das amostras pela transmitância de radiação visível (660nm) em um espectrofotômetro FEMTO (modelo: 800XI) em uma cubeta de quartzo com um caminho ótico de $1 \mathrm{~cm}$, conforme metodologia descrita em trabalho anterior ${ }^{[15]}$.

A análise de infravermelho foi realizada em um aparelho FTIR VERTEX 70 da Bruker com 256 scans, usando pastilha de $\mathrm{KBr}$. Obteve-se o grau de desacetilação (GD) através de metodologia descrita por Brugnerotto et al. ${ }^{[16]}$, através da integração das áreas das bandas em $1320 \mathrm{~cm}^{-1}$ e $1420 \mathrm{~cm}^{-1}$, referentes respectivamente aos grupamentos $\mathrm{N}$-acetilglucosamina e glucosamina, usando o software Origin 6.0. A integração foi realizada usando a linha de base dos picos e o procedimento foi realizado em triplicata para cada pico, onde uma média das áreas foi estabelecida e usada para o calculo do GD, usando a Equação 6:

$$
\mathrm{GD}=100-\left[31,92 \times\left(\mathrm{A}_{1320} / \mathrm{A}_{1420}\right)-12,2\right]
$$

\section{Resultados e Discussão}

A quitosana obtida a partir de quitina pode ser encontrada em uma variedade de animais marinhos, insetos e fungos. As cascas de crustáceos contêm 15 a $20 \%$ de quitina, 25 a $40 \%$ de proteínas e 40 a $55 \%$ de carbonato de cálcio ${ }^{[17]}$.

A amostra de quitosana obtida foi caracterizada quanto as suas propriedades, que dependem fortemente da proporção relativa das unidades 2-amino-2-deoxi$D$-glicopiriranose (glucosamina) e 2-acetamido-2deoxi- $D$-glicopiranose (acetil-glucosamina). O grau de desacetilação (GD) é definido como a fração de grupos amino na cadeia polimérica. Este parâmetro, juntamente com a massa molar, são determinantes das características deste polissacarídeo em solução, além de exercer grande influência nas propriedades físicas, químicas 
e biológicas ${ }^{[18,19]}$. Quando o GD da quitina é superior a $70 \%$, a quitosana torna-se solúvel em soluções aquosas ácidas e se comporta como um polieletrólito catiônico, onde se classifica como uma quitosana adequada para diversas aplicações. As propriedades físicas e químicas da quitina e de seus derivados $\mathrm{N}$-desacetilados são diferenciadas $^{[20]}$, onde a quitosana comercial possui um GD com variação média 70 a $95 \%$, com massa molar na faixa de $10^{4}-10^{6}$ g.mol ${ }^{-1[21]}$.

A Figura 3 ilustra os espectros no infravermelho das amostras de quitosana produzida $\left(\mathrm{Q}_{\mathrm{P}}\right)$, convencional $\left(Q_{V}\right)$ e comercial $\left(Q_{C}\right)$ e da quitina. A cadeia da quitosana comumente apresenta duas bandas de adsorção forte do tipo amida em 1654 e $1596 \mathrm{~cm}^{-1}$, correspondentes à deformação simétrica e assimétrica da amida I e II, respectivamente. Os grupamentos hidrocarbônicos da quitosana apresentam picos de absorção em $2900 \mathrm{~cm}^{-1}$ e os grupamentos acetil-glucosamina em $1320 \mathrm{~cm}^{-1}$. As unidades glucosamina da quitosana apresentam absorção em $1420 \mathrm{~cm}^{-1}$ e $3300 \mathrm{~cm}^{-122]}$.

Observa-se na Figura 3 a que existe grande semelhança entre os espectros das amostras $\mathrm{Q}_{\mathrm{P}}$ e $\mathrm{Q}_{\mathrm{C}}$, um indicativo que a conversão da quitina para quitosana por radiação de micro-ondas ocorreu de forma satisfatória.

Por outro lado, analisando a Figura 3b, observa-se que a amostra $Q_{v}$ apresenta similaridades com as amostras $\mathrm{Q}_{\mathrm{p}}$ e $\mathrm{Q}_{\mathrm{C}}$, porém apresenta um pico extra em torno de $1700 \mathrm{~cm}^{-1}$. Este pico pode ser atribuído ao estiramento de grupos carbonila, que também aparecem no espectro da quitina, o que é um indicativo de desacetilação parcial dos grupos acetamido da quitina.

Segundo Dash et al. ${ }^{[23]}$, a banda em $1320 \mathrm{~cm}^{-1}$ é similar para a quitina e seus derivativos, associada ao estiramento C-N do grupo acetilglucosamina. Já a banda cuja absorção é centralizada em $1420 \mathrm{~cm}^{-1}$ corresponde a deformação angular do grupo da glucosamina. Foram integradas as áreas dos picos em questão, determinando-se o GD por infravermelho. As amostras $Q_{P}, Q_{C}$ e $Q_{V}$ também tiveram o grau de desacetilação determinados por titulação, conforme consta na Figura 4. Observa-se a existência de dois pontos de inflexão para todas as curvas. Os valores do GD para as amostras determinados por titulação e por Infravermelho constam na Tabela 1.

Observa-se na Tabela 1 que as duas técnicas utilizadas para análise do GD apresentaram resultados com uma diferença entre 2 e $5 \%$ entre si. $A$ amostra $Q_{V}$ produzida apresentou um grau de desacetilação inferior a $70 \%$ pelas duas técnicas empregadas, o que é insuficiente para que apresente boa solubilidade. No entanto, as amostras $Q_{p}$ e $\mathrm{Q}_{\mathrm{C}}$ apresentaram GD concordante com os valores da literatura, pois é sabido que as quitosanas comerciais possuem, geralmente, grau de desacetilação variando de 70 a $95 \%$ [19].

Kurita $^{[18]}$ define que dentre os métodos de determinação do grau de desacetilação, o método por infravermelho é conveniente devido a sua praticidade, porém deve-se observar cuidados de forma a estabelecer reprodutibilidade, pois, dependendo da marcação da linha de base, pode-se obter diferentes valores para a área da banda, podendo ocasionar uma maior incerteza no seu resultado. De fato, Dash et al. ${ }^{[23]}$ afirma que considerando
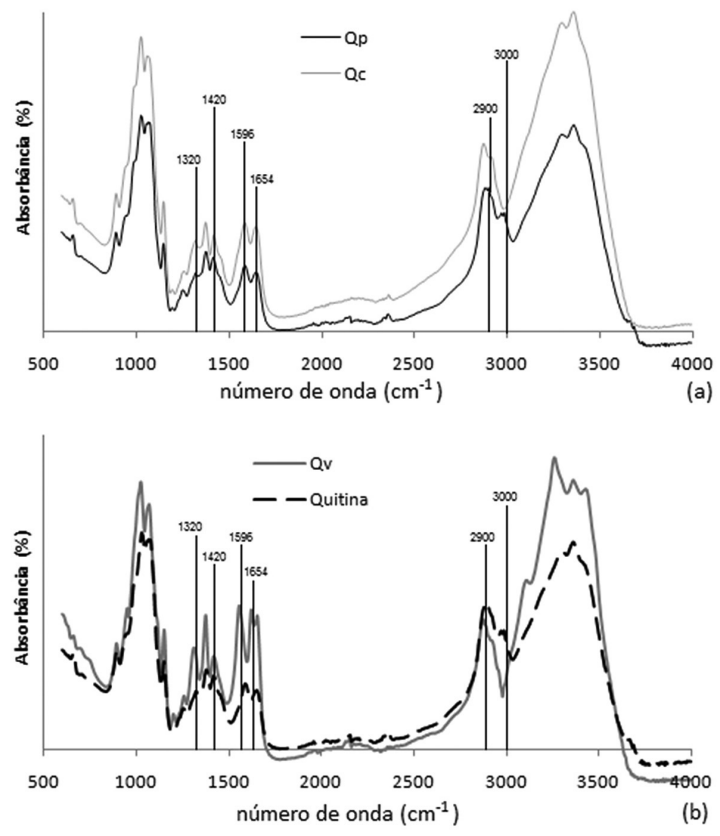

Figura 3. Espectro de infravermelho das amostras: (a) $Q_{P}$ e $Q_{C}$; (b) $\mathrm{Q}_{\mathrm{V}}$ e quitina.

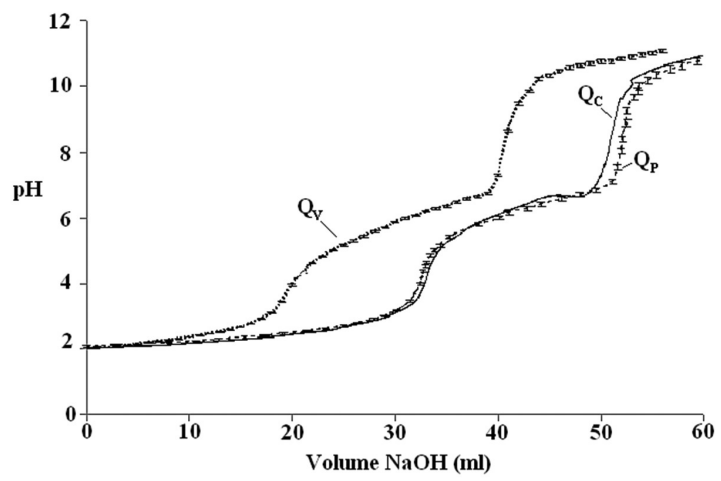

Figura 4. Curvas de titulação potenciométrica para as amostras: $Q_{P}$ e $Q_{C}$ e $Q_{V}$

Tabela 1. Valores de grau de desacetilação obtidos pelas técnicas de infravermelho e titulação potenciométrica para a quitosana produzida e para a quitosana comercial.

\begin{tabular}{lccc}
\hline & $\mathbf{Q}_{\mathbf{p}}$ & $\mathbf{Q}_{\mathrm{C}}$ & $\mathbf{Q}_{\mathbf{V}}$ \\
\hline $\mathrm{GD}_{\text {FTIR }}$ & 81 & 76 & 67 \\
$\mathrm{GD}_{\text {Titulaçăo }}$ & 77 & 71 & 65 \\
\hline
\end{tabular}

que o erro na determinação por FTIR se situa em torno de $5 \%$, é possível confirmar que a equação proposta por Brugnerotto et al. ${ }^{[16]}$ é válida para acompanhar a reação de desacetilação da quitina.

Neste estudo, observou-se que a técnica de infravermelho pode ser usada para estabelecer um grau comparativo entre diferentes tipos de amostras, porém o método por titulação potenciométrica, apesar de ser mais laborioso, produz um resultado mais confiável e preciso, já que os parâmetros são controlados através da quantidade de repetições, o que conduz para um resultado com menor margem de erro. No entanto, ambos os métodos adotados 
para determinação do GD são válidos para caracterização da amostra de quitosana e servem de base comparativa entre as amostras.

A desacetilação da quitina foi realizada em meio alcalino usando aquecimento por radiação de microondas $\left(\mathrm{Q}_{\mathrm{p}}\right) \mathrm{e}$, convencionalmente, através de aquecimento sob refluxo $\left(\mathrm{Q}_{\mathrm{V}}\right)$. O consumo energético total da reação usando radiação por micro-ondas a $270 \mathrm{~W}$ por $30 \mathrm{~min}$, foi de $486 \mathrm{~kJ}$, enquanto que na reação convencional, a reação ocorrida em manta de aquecimento de $700 \mathrm{~W}$ sob refluxo por $2 \mathrm{~h}$ teve um consumo de $5040 \mathrm{~kJ}$. Logo, conclui-se que a reação convencional deve empregar tempos ainda maiores do que o utilizado neste estudo para aumentar a conversão dos grupos acetamido em amino, evidenciando a eficácia do método de radiação por microondas. $\mathrm{A}$ amostra $\mathrm{Q}_{\mathrm{p}}$ foi produzida em um processo que consumiu cerca de $10 \%$ da energia utilizada no processo convencional, com maior grau de desacetilação do que a amostra convencional. Com a produção de quitosana sendo empregada em maior escala, o método de microondas apresenta grandes vantagens se comparado ao método tradicional de aquecimento, porque além de otimizar tempo, economiza grande quantidade de energia $^{[9]}$.

Outra propriedade importante de caracterização da quitosana é a viscosidade e a massa molar viscosimétrica. $\mathrm{A}$ amostra $\mathrm{Q}_{\mathrm{V}}$ apresentou solubilidade apenas parcial, não sendo possível a determinação da viscosidade intrínseca e sua correspondente massa molar viscosimétrica. A Figura 5 ilustra o perfil da viscosidade específica reduzida em função da concentração da solução para a amostra $Q_{C}$ e $Q_{p}$. Observa-se que a amostra $Q_{p}$ apresentou valores de viscosidade mais elevados do que a amostra $\mathrm{Q}_{C}$ para concentrações inferiores a $0,5 \mathrm{~g} / \mathrm{mL}$, onde no entanto, ocorre um ponto de superposição na concentração de $0,1 \mathrm{~g} / \mathrm{mL}$, com valores de viscosidade muito similares $(\sim 1200 \mathrm{~mL} / \mathrm{g})$. A viscosidade intrínseca foi determinada graficamente, através de regressão linear dos pontos, e a massa molar viscosimétrica media dos polímeros foi estimada a partir desta usando a Equação 5; os valores constam na Tabela 2.

Nos estudos feitos por Signini e Campana Filho $^{[24]}$, amostras de quitosanas comerciais avaliadas apresentaram os valores de viscosidade intrínseca variando entre 613 a $725 \mathrm{~mL} / \mathrm{g}$. A viscosidade intrínseca da quitosana produzida e comercial apresentaram valores de 1371 e $1173 \mathrm{~mL} / \mathrm{g}$, respectivamente. Observa-se que a amostra $\mathrm{Q}_{\mathrm{p}}$ apresentou massa molar maior do que $\mathrm{Q}_{\mathrm{C}}$, com valores respectivos de $41,26 \times 10^{4}$ e $33,61 \mathrm{~g} / \mathrm{mol}$, porém se mantendo na mesma ordem de grandeza. Estes valores estão de acordo com os da literatura, pois estes polissacarídeos costumam apresentar valores na faixa de $10^{4}-10^{6} \mathrm{~g} \cdot \mathrm{mol}^{-1[21]}$.

Investigou-se também a solubilidade das amostras $\mathrm{Q}_{C}, \mathrm{Q}_{\mathrm{V}}$ e $\mathrm{Q}_{\mathrm{p}}$ de forma comparativa. Ao adicionar a amostra $\mathrm{Q}_{\mathrm{P}}$ em solução $2 \%(\mathrm{v} / \mathrm{v})$ de ácido acético sob agitação, observou-se que a mesma dissolveu em 5 min, a temperatura ambiente. Para a amostra $Q_{C}$ e $\mathrm{Q}_{\mathrm{V}}$, foi necessário aquecer a solução a $50^{\circ} \mathrm{C}$ por $30 \mathrm{~min}$ para que ocorresse solubilização parcial. Para fins quantitativos, avaliou-se a transmitância das soluções

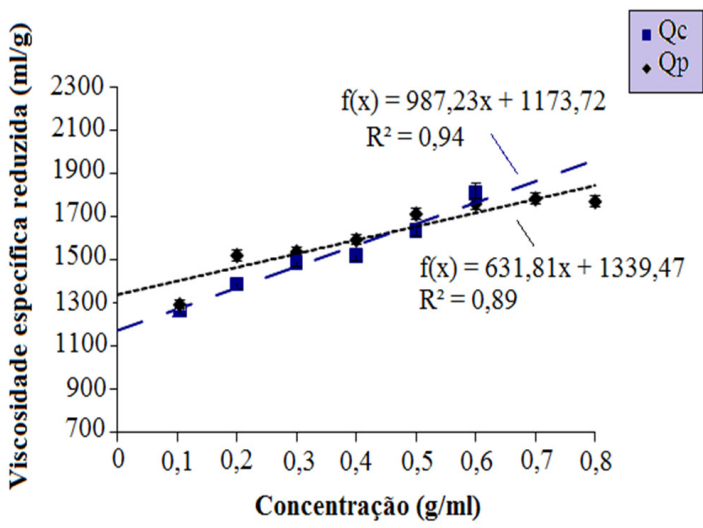

Figura 5. Curvas da viscosidade específica reduzida da quitosana produzida e da quitosana comercial em função da concentração da solução.

Tabela 2. Valores de viscosidade intrínseca e massa molar viscosimétrica média obtidos para a quitosana comercial e para a quitosana produzida.

\begin{tabular}{ccc}
\hline & {$[\eta](\mathbf{m L} / \mathbf{g})$} & $\mathbf{M}_{\mathbf{Z}} \times \mathbf{1 0}^{\mathbf{4}}(\mathbf{g} / \mathbf{m o l})$ \\
\hline $\mathbf{Q}_{\mathbf{P}}$ & 1371 & 41,26 \\
$\mathbf{Q}_{\mathrm{C}}$ & 1173 & 33,61 \\
\hline
\end{tabular}

em um espectrofotômetro de UV-visível a $600 \mathrm{~nm}$. A solução da amostra $Q_{C}$ e $Q_{V}$ apresentaram valores de transmitância de 5 e 3\%, indicando alta concentração de partículas em suspensão, que espalham e refletem a luz. Já a solução da amostra $\mathrm{Q}_{\mathrm{p}}$ apresentou transmitância de $71 \%$, indicando alta solubilidade em meio aquoso ácido. A maior solubilidade da amostra $\mathrm{Q}_{\mathrm{p}}$ em relação a amostra $\mathrm{Q}_{\mathrm{C}}$ e $\mathrm{Q}_{\mathrm{V}}$ pode ser entendida em função do número de grupos amino por cadeia polimérica. A quitosana produzida pode - apesar de apresentar uma maior massa molar - devido ao maior grau de desacetilação, apresentar um maior número de grupos amino, que em meio ácido (solução de ácido acético a $2 \%(\mathrm{v} / \mathrm{v})$ interagem de maneira mais favorável com o solvente, resultando em uma solvatação mais eficiente e na sua consequente solubilização.

\section{Conclusão}

Obteve-se de forma bem sucedida quitosana a partir do exoesqueleto de caranguejo-uçá através da metodologia descrita neste trabalho. A análise comparativa das amostras de quitosana $\mathrm{Q}_{\mathrm{p}}$ e $\mathrm{Q}_{\mathrm{v}}$, produzidas pelos métodos por radiação de micro-ondas e via convencional mostrou que o método por radiação mostrou-se particularmente vantajoso, pois neste processo houve uma maior conversão dos grupos acetamido em amino, com um consumo energético de $10 \%$ comparado ao método convencional. O estudo comparativo das propriedades da amostra $Q_{P}$ com a amostra comercial $\left(Q_{C}\right)$ revelou que a amostra $Q_{p}$ apresentou maior GD, maior viscosidade intrínseca e massa molar, e ainda maior solubilidade a frio do que a amostra $\mathrm{Q}_{\mathrm{C}}$, indicando que o método é eficiente $\mathrm{e}$ o processo agrega economia de tempo e energia. 


\section{Referências Bibliográficas}

1. Krajewska, B. - Enzyme Microb. Tech., 35, p.126 (2004). http://dx.doi.org/10.1016/j.enzmictec.2003.12.013

2. Sinha, V. R.; Singla, A. K.; Wadhawan, S.; Kaushik, R.; Kumria, R.; Bansal, K. \& Dhawan, S. - Int. J. Pharm., 274. p.1 (2004). PMid:15072779. http://dx.doi.org/10.1016/j. ijpharm.2003.12.026

3. Assis, O. B. G. \& da Silva, V. L. - Polímeros, 13, p.223 (2003). http://dx.doi.org/10.1590/S0104-14282003000400006

4. Sorlier, P.; Viton, C. \& Domard, A. - Biomacromolecules, 4 p.1336 (2002). http://dx.doi.org/10.1021/bm0256146

5. Dos Santos, J. E.; Soares, J. P.; Dockal., E. R., Campana Filho, S. P. \& Cavalheiro E. T. G. - Polímeros, 13, p.242 (2003).

6. De Castro, A. C. L.; Correia, M. M. F.; Nascimento, A. R.; Piedade Júnior, R. N.; Gama, L. R. M.; Sousa, M. M.; Sena, A. C. S. \& Sousa, R. C. C. - Amazônia: Cienc. \& Desenv., 3, p.17 (2008).

7. Cahú, T. B.; Santos, S. D.; Mendes, A.; Córdula, C. R.; Chavante, S. F.; Carvalho, L. B.; Nader, H. B. \& Bezerra, R. S. - Proces. Biochem., 7, p.570 (2012). http://dx.doi. org/10.1016/j.procbio.2011.12.012

8. Campana Filho, S. P.; Brito, D.; Curti, E.; Abreu, F. R.; Cardoso, M. B.; Battisti, M. V.; Sim, P. C.; Goy, R. C.; Signini, R. \& Lavall, R. L. - Quim. Nova, 30, p.644 (2007).

9. De Moura, C. M.; De Moura, J. M.; Soares, N. M. \& Pinto, L. A. A. - Chem. Eng. Proces., 50, p.351 (2011).

10. Campana Filho, S. P. \& Signini, R. - Polímeros, 11, p.169 (2001). http://dx.doi.org/10.1590/S010414282001000400006

11. Sagheer, F. A. A.; Sughayer, M. A. A.; Muslim, S. \& Elzabee, M. Z. - Carbohyd. Polym., 77, p.410 (2009). http://dx.doi.org/10.1016/j.carbpol.2009.01.032

12. De Oliveira, B. S. \& Nunes M. L. - Scie. Plena, 7, 041501 (2011).
13. Abreu, F. O. M. S.; Bianchini, C.; Forte, M. M. C. \& Kist, T. B. L. - Carbohyd. Polym., 74, p.283 (2008). http:// dx.doi.org/10.1016/j.carbpol.2008.02.017

14. Rinaudo, M.; Milas, M. \& Dung, L. P. - Int. J. BioI. Macromol., 15, p.281 (1993). http://dx.doi. org/10.1016/0141-8130(93)90027-J

15. Abreu, F. O.; Bianchini, C.; Kist, T. B. \& Forte, M. M. C. - Polym. Int., 58, p.1267 (2009). http://dx.doi. org/10.1002/pi.2657

16. Brugnerotto, J.; Lizardi, J.; Goycoolea, F. M.; ArguellesMonal, W.; Desbrières, J. \& Rinaudo, M. - Polymer, 42, p.3569 (2001). http://dx.doi.org/10.1016/S00323861(00)00713-8

17. Mathur, N. K. \& Narang, C. K. - J. Chem. Educ., 67 (11), p.938 (1990). http://dx.doi.org/10.1021/ed067p938

18. Kurita, K. - Prog. Polym. Sci., 26, p.1921 (2001). http:// dx.doi.org/10.1016/S0079-6700(01)00007-7

19. Montembault, A.; Viton, C. \& Domard A. - Biomaterials, 26, p.933 (2005). PMid:15353205. http://dx.doi.org/10.1016/j. biomaterials.2004.03.033

20. Dung, P. L.; Milas, M.; Rinaudo, M. \& Desbrières, J. - Carboydr. Polym., 24, p.209 (1994). http://dx.doi. org/10.1016/0144-8617(94)90132-5

21. Kubota, N. \& Eguchi, Y. - Polym. J., 29, p.123 (1997). http://dx.doi.org/10.1295/polymj.29.123

22. De, S. \& Robinson, D. - J. Control Release, 89, p.101 (2003). http://dx.doi.org/10.1016/S0168-3659(03)00098-1

23. Dash, M.; Chiellini, F.; Fernandez, E. G.; Piras, A. M. \& Chiellini, E. - Carbohyd. Polym., 86, p.65 (2011). http:// dx.doi.org/10.1016/j.carbpol.2011.04.010

24. Signini, R. \& Campana Filho, S. P. - Polímeros, 11, p.58 (2001). http://dx.doi.org/10.1590/S010414282001000200007

Enviado: 08/02/12 Reenviado: $17 / 07 / 12$ Aceito: $21 / 08 / 12$ 